\title{
Asset Pricing with Limited Risk Sharing and Heterogeneous Agents*
}

\author{
Francisco Gomes ${ }^{\dagger}$
}

LBS and CEPR

and

Alexander Michaelides ${ }^{\ddagger}$

LSE, CEPR and FMG

March 2005

\footnotetext{
*We would like to thank Nicholas Barberis, Suleyman Basak, Joao Cocco, Joao Gomes, Wouter den Haan, John Heaton, Nobuhiro Kiyotaki, Anna Pavlova, Valery Polkovnichenko, Randi Rosenblatt, Kjetil Storesletten, Raman Uppal, Amir Yaron, Lu Zhang, and seminar participants at the NBER Summer Meeting, the Utah Winter Finance Conference, the Society for Economic Dynamics Annual Meeting, University of Copenhagen, University of Gotemburg, London Business School, London School of Economics, University of North Carolina at Chapel Hill, and Oslo University for helpful comments and discussions. All remaining errors are our own.

†Address: London Business School, Regent's Park, London NW1 4SA, United Kingdom. Phone: (44) 2072625050. E-mail: fgomes@london.edu

$\ddagger$ Address: Department of Economics, London School of Economics, Houghton Street, London, WC2A 2AE, United Kingdom. Email: A.Michaelides@lse.ac.uk.
} 


\begin{abstract}
We solve a model with incomplete markets and heterogeneous agents that generates a large equity premium, while simultaneously matching stock market participation and individual asset holdings. The high risk premium is driven by incomplete risk sharing among stockholders, which results from the combination of borrowing constraints and (realistically) calibrated life-cycle earnings profiles, subject to both aggregate and idiosyncratic shocks. We show that it is challenging to simultaneously match aggregate quantities (asset prices) and individual quantities (asset allocations). Furthermore, limited participation has a negligible impact on the risk premium, contrary to the results of models where it is imposed exogenously.

JEL Classification: E21, G11.
\end{abstract}

Key Words: Equity Premium, Preference Heterogeneity, Incomplete Risk Sharing, LifeCycle Models, Limited Stock Market Participation. 


\section{Introduction}

We present an asset pricing model that closely matches aggregate asset pricing moments (mean and standard deviation of stock returns and T-bill returns), while simultaneously matching individual allocations (stock market participation rate and asset holdings). The key ingredients of the model are household heterogeneity and market incompleteness.

Households are heterogeneous along several different dimensions. First, they receive different uninsurable labor income shocks. Second we have a life-cycle model and therefore young agents, mid-life households and retirees all behave differently. Third, we introduce a fixed cost of stock market participation, and thus agents who have paid the cost have access to a larger investment opportunity set. Fourth, households have Epstein-Zin preferences (Epstein and Zin (1989)) and we consider heterogeneity in both risk aversion and elasticity of intertemporal substitution.

Market incompleteness results from both aggregate and (uninsurable) idiosyncratic shocks, combined with borrowing constraints. Aggregate uncertainty and the household preference parameters are calibrated to match the second moments of equity returns and (stockholders') consumption growth. The idiosyncratic uncertainty is driven by a (realistically) calibrated life-cycle stochastic earnings profile that agents cannot fully insure, and against which they cannot borrow. In this context, our baseline model yields a high risk premium (4.33\%) and a low riskless rate $(1.72 \%)$ with coefficients of relative risk aversion no larger than 5 . The volatility of consumption growth, for both stockholders and non-stockholders, is also consistent with the data.

Previous literature (e.g. Saito (1995), Basak and Cuoco (1998), or Guvenen (2003)) has argued that (exogenous) limited stock market participation can help to explain the equity risk premium puzzle. ${ }^{1}$ In our model limited participation is derived endogenously and, consistent with the data, the non-participants are significantly less wealthy than households that own stocks. ${ }^{2}$ Therefore, excluding those households from the equity market has a

\footnotetext{
${ }^{1}$ The models in Heaton and Lucas (2000) and Polkovnichenko (2004) also have exogenous participation constraints, but obtain a smaller impact on the equity premium.

${ }^{2}$ According to the latest numbers from the Survey of Consumer Finances, the participation rate is $88.84 \%$ among households with wealth above the median, and only $15.21 \%$ for those with wealth below the median.
} 
negligible impact on the risk premium. Only by assuming extremely high entry costs, or by imposing the participation constraint exogenously, would it be possible to exclude rich households and thus produce a significant increase in the risk premium. ${ }^{3}$

We rationalize the modest participation rates observed in the data (Mankiw and Zeldes (1991)) by introducing a small stock market entry cost. Households with very low risk aversion $(R A)$ and low elasticity of intertemporal substitution (EIS) do not particularly care about hedging background risk (because of the low $R A$ ) or about saving for retirement (because of the low EIS). Therefore, they behave essentially as in the Deaton (1991) infinite horizon model. They smooth earnings shocks with a small buffer stock of assets, and most of them never invest in equities. Investors with high risk aversion and high EIS, on the other hand, participate in the stock market from early on. They accumulate more wealth and have a stronger incentive to pay the fixed cost. It is important to point out that, this self-selection of more risk-averse investors as stockholders, is not driving our equity premium results. As previously mentioned, the equity premium remains essentially unchanged when we eliminate the participation constraints and all households invest in equities.

Asset-pricing models usually assume that equity exists in positive net supply, while the riskless asset exists in zero net supply. ${ }^{4}$ We instead explicitly include government bonds that exist in positive net supply. In equilibrium, the zero-net-supply assumption implies that the representative consumer must invest all of her wealth in the risky asset. Furthermore, in models with limited stock market participation, this implies that a significant fraction of the population must hold levered positions in equities. Those predictions are in clear contrast with the empirical evidence on household-level asset holdings (see, for instance, Poterba and Samwick (2001), Ameriks and Zeldes (2001), or Guiso, Haliassos and Japelli (2002)).

Matching the participation rate and asset allocation decisions implies more than an increase in the complexity of the model. We quantify an important trade-off between consistency with asset pricing moments, and consistency with household portfolios and the The median wealth for stockholders is $\$ 154,600$, while the median wealth for non-stockholders is $\$ 7,300$.

${ }^{3}$ In Cao, Wang and Zhang (forthcoming) limited participation can arise endogenously in a single-period mean-variance equilibrium due to the presence of model uncertainty and heterogeneity in uncertainty aversion. In their model, limited participation can actually decrease the equity premium.

${ }^{4}$ Alternatively the riskless rate is specified exogenously and the supply of bonds is perfectly elastic. 
participation rate. If the riskless asset exists in positive supply, households require a higher riskless rate to induce them to hold bonds. In addition, their consumption volatility falls as a smaller fraction of their wealth is now invested in the risky security. These two effects lead to a lower equity premium. In fact, as we decrease the supply of the riskless asset towards zero, our model can easily match the historical equity premium with a low riskless rate and low consumption volatility. Furthermore, if we do not care about matching the participation rate and the wealth distribution, then we can have a model without preference heterogeneity. Such a model matches aggregate moments (asset prices and consumption volatility) quite well, and replicates the unconditional results in Storesletten et al. (2001), or in the representative agent framework of Campbell and Cochrane (1999), among others.

Our paper is part of a large literature investigating the implications of heterogeneous agent models with incomplete markets and/or limited stock market participation for asset pricing. ${ }^{5}$ We also build on the literature on asset allocation with undiversifiable labor income risk. ${ }^{6}$ The closest papers to ours are Saito (1995), Basak and Cuoco (1998), Heaton and Lucas (2000), Storesletten, Telmer and Yaron (2001) and Guvenen (2003). Storesletten et al. (2001) also have a life-cycle model, but do not have participation costs, preference heterogeneity or retirement income (social security system). We use the first two features to match the stock market participation rate, and the third to obtain a more accurate measure of households' earnings uncertainty. Heaton and Lucas (2000) solve an overlapping generations exchange economy where households live for two periods. They model (exogenous) limited

\footnotetext{
${ }^{5}$ For instance, Aiyagari and Gertler (1991), Telmer (1993), Allen and Gale (1994), den Haan (1994), Lucas (1994), He and Modest (1995), Heaton and Lucas (1996), Krusell and Smith (1997), Basak and Cuoco (1998), Luttmer (1999), Heaton and Lucas (2000), Abel (2001), Storesletten, Telmer and Yaron (2001), Constantinides, Donaldson and Mehra (2002), Calvet, Gonzalez-Eiras, and Sodini (2002), and Guvenen (2003). See also the empirical work by Brav, Constantinides and Geczy (2002), Attanasio, Banks and Tanner (2002), and Vissing-Jorgensen (2002b).

${ }^{6}$ See, for instance, Heaton and Lucas (1997), Bertaut and Haliassos (1997), Koo (1998), Cocco, Gomes and Maenhout (1999), Dammon, Spatt and Zhang (2001), Campbell, Cocco, Gomes and Maenhout (2001), Viceira (2001), Hu (2001), Davis, Kubler and Willen (2002), Polkovnichenko (2002), Haliassos and Michaelides (2003), Cocco (forthcoming), Yao and Zhang (forthcoming), Gomes and Michaelides (2003 and forthcoming), and Benzoni, Collin-Dufresne and Goldstein (2004).
} 
participation and incomplete risk sharing. Guvenen (2003), Basak and Cuoco (1998) and Saito (1995) also match the stock market participation rates. Relative to these models, we endogeneize the participation decision. Moreover, we do not have perfect risk sharing among stockholders. These differences are crucial since our risk premium is driven by the imperfect risk sharing across shareholders, and is almost unaffected by limited participation. In addition, we have a life-cycle model with a calibrated earnings process and retirement income, thus closely matching the level of earnings uncertainty in the data. Finally, unlike all these papers, we explicitly take into account government debt, which has important asset pricing implications.

The paper is structured as follows. Section 2 outlines the model and calibration while Section 3 discusses the baseline results. Section 4 studies the determinants of the equity premium, while Section 5 offers additional comparative statics. Section 6 concludes.

\section{The Model}

\subsection{Outline}

The model is solved at an annual frequency. Households have a finite horizon divided into two main phases: working life and retirement. During working life they receive a wage income against which they cannot borrow, and subject to uninsurable shocks. At retirement they receive a pension that is financed by taxes on current workers' wages. Households can invest in two alternative assets: a claim to the risky capital stock (equity) and a riskless government bond. Before investing in equity for the first time they must pay a fixed participation cost.

Firms are perfectly competitive, and combine capital and labor, using a constant returns to scale technology, to produce a non-durable consumption good. The government taxes wages to finance the social security scheme (pension income), while taxes on both capital gains and bequests are used to finance government expenditures and the interest payments on public debt. 


\subsection{Production technology}

\subsubsection{Production function}

The technology in the economy is characterized by a standard Cobb-Douglas production function, with total output at time $t$ given by

$$
Y_{t}=Z_{t} K_{t}^{\alpha} L_{t}^{1-\alpha}
$$

where $K$ is the total capital stock in the economy, $L$ is the total labor supply and $Z$ is a stochastic productivity shock which follows the process

$$
\begin{gathered}
Z_{t}=G_{t} U_{t} \\
G_{t}=(1+g)^{t}
\end{gathered}
$$

Secular growth in the economy is determined by the constant $g(>0)$, while the productivity shocks $U_{t}$ follow a two-state Markov chain capturing the average business cycle duration.

Firms make decisions after observing aggregate shocks. Therefore, they solve a sequence of static maximization problems with no uncertainty, and factor prices (wages, $W_{t}$, and return on capital, $R_{t}^{K}$ ) are given by the firm's first-order conditions

$$
W_{t}=(1-\alpha) Z_{t}\left(K_{t} / L_{t}\right)^{\alpha}
$$

and

$$
R_{t}^{K}=\alpha Z_{t}\left(L_{t} / K_{t}\right)^{1-\alpha}-\delta_{t}
$$

where $\delta_{t}$ is the depreciation rate.

\subsubsection{Stochastic depreciation}

Standard frictionless production economies cannot generate sufficient return volatility, since agents can adjust their investment plans to smooth consumption over time (see Jermann (1998) or Boldrin, Christiano and Fisher (2001)). This usually motivates adjustment costs for capital, which create fluctuations in the price of capital and increase return volatility (see also Cochrane (1991)). ${ }^{7}$

\footnotetext{
${ }^{7}$ Adjustment costs are also very important for a realistic characterization of aggregate investment flows. See, for example, Abel and Eberly (1994) or Eberly (1997).
} 
Since we have incomplete markets, different stockholders have different stochastic discount factors. They will therefore disagree on the solution to the optimal intertemporal decision problem of the firm (see Grossman and Hart (1979)). This is not a concern here because there is no intertemporal dimension to the firm's problem, but introducing adjustment costs would change that. ${ }^{8}$ Recent papers with production economies and incomplete markets have captured the adjustment cost effect by assuming a stochastic depreciation rate for capital (Storesletten et al. (2001), Krueger and Kubler (2004), and Gottardi and Kubler (2004)). We follow the same route and assume that the depreciation rate is given by

$$
\delta_{t}=\delta+s * \eta_{t}
$$

where $\eta_{t}$ is an i.i.d. standard normal and $s$ is a scalar. Therefore, $\delta_{t}$ is a general measure of economic depreciation, combining physical depreciation, adjustment costs, capital utilization and investment-specific productivity shocks. ${ }^{9}$

In the baseline case we assume that $\eta_{t}$ is uncorrelated with the productivity shock $U_{t}$. A positive correlation might be more intuitive, reflecting higher capital utilization in booms, and therefore we will also consider this case.

\subsection{The government sector and social security}

A social security system is important to provide the model with a realistic labor income process. If we were to ignore social security transfers we would significantly increase households' income risk and wealth accumulation. The government sector is crucial to model government bonds in positive supply, so as to match the average portfolio allocations in the data.

\footnotetext{
${ }^{8}$ Guvenen (2003) introduces adjustment costs in a model with restricted stock market participation, but in his model the participation constraint is exogenous and there is perfect risk sharing among stockholders. Therefore, there is a unique stochastic discount factor for pricing capital.

${ }^{9}$ Hercowitz (1986) and Greenwood, Hercowitz and Huffman (1988) use the same approach to model fluctuations in capital utilization, while Greenwood, Hercowitz and Krusell (1997) use it to model investmentspecific technological shocks as a reduced form for vintage capital models.
} 


\subsubsection{The social security system}

The social security budget is balanced in all periods so we can discuss it separately. Given a value for the replacement ratio of working life earnings (denoted by $\lambda$ ), a proportional social security tax rate on labor income (denoted by $\tau_{s}$ ) is determined endogenously. This tax rate ensures that the social security taxes are equal to total retirement benefits, taking into account the demographic weights and survival probabilities.

\subsubsection{The government sector}

The government's budget constraint (excluding social security) is

$$
G C_{t}+R_{t}^{B} B_{t}=B_{t+1}-B_{t}+T_{t}
$$

where $G C$ is government consumption, $B$ is public debt, $R^{B}$ is the interest rate on government bonds, and $T$ denotes the tax revenues. Tax proceeds arise from proportional taxation on capital (tax rate $\tau_{K}$ ) and a $100 \%$ tax rate on bequests $(E)$. The steady-state level of government debt (as a fraction of GDP) is calibrated to the data. Government consumption is determined as the residual from (7), given the (exogenous) level of debt, the (exogenous) tax rate on capital, and the (endogenous) interest rate on bonds. These expenditures do not enter the agents' utility function.

\subsection{Households and financial markets}

\subsubsection{Preferences}

Time is discrete. We follow the convention in life-cycle models and let adult age $(a)$ correspond to effective age minus 19. Each period corresponds to one year and agents live for a maximum of $81(A)$ periods (age 100). The probability that a consumer is alive at age $(a+1)$, conditional on being alive at age $a$, is denoted by $p_{a}\left(p_{0}=1\right)$. Households have Epstein-Zin preferences (Epstein and Zin (1989)) defined over a single non-durable consumption good. Let $C_{a}$ and $X_{a}$ denote consumption and wealth (cash-on-hand) at age 
$a$, respectively. Household preferences are defined by

$$
V_{a}=\left\{\left(1-\beta p_{a}\right) C_{a}^{1-1 / \psi}+\beta p_{a}\left(E_{a}\left(V_{a+1}^{1-\rho}\right)\right)^{\frac{1-1 / \psi}{1-\rho}}\right\}^{\frac{1}{1-1 / \psi}}
$$

where $\rho$ is the coefficient of relative risk aversion, $\psi$ is the elasticity of intertemporal substitution and $\beta$ is the discount factor.

\subsubsection{Labor endowment}

Before retirement all households supply labor inelastically. The stochastic process for individual labor income $\left(H_{a t}^{i}\right)$ is given by ${ }^{10,11}$

$$
H_{a t}^{i}=W_{t} L_{a}^{i}
$$

where $L_{a}^{i}$ is the household's labor endowment (labor supply scaled by productivity) and $W_{t}$ is the aggregate wage per unit of productivity. The household's labor endowment is specified to match the standard stochastic earnings profile in life-cycle models of savings and

portfolio choice. More precisely, labor income productivity combines both permanent $\left(P_{a}^{i}\right)$ and transitory $\left(\varepsilon^{i}\right)$ shocks with a deterministic age-specific profile:

$$
\begin{gathered}
L_{a}^{i}=P_{a}^{i} \varepsilon^{i} \\
P_{a}^{i}=\exp (f(a)) P_{a-1}^{i} \xi^{i}
\end{gathered}
$$

where $f(a)$ is a deterministic function of age, capturing the typical hump-shape profile in life-cycle earnings. We assume that $\ln \varepsilon^{i}$, and $\ln \xi^{i}$ are each independent and identically distributed with mean $\left\{-.5 * \sigma_{\varepsilon}^{2},-.5 * \sigma_{\xi}^{2}\right\}$, and variances $\sigma_{\varepsilon}^{2}$ and $\sigma_{\xi}^{2}$, respectively.

Retirement is exogenous and deterministic. All households retire at age $65\left(a^{R}=46\right)$ and retirement earnings are given by: $\lambda P_{a^{R}}^{i} W_{t}$, where $\lambda$ is the replacement ratio.

\footnotetext{
${ }^{10}$ We now include a superscript $i$ to identify household specific variables.

${ }^{11}$ Lettau (2003) shows that allowing for a labor leisure choice does not meaningfully affect the asset pricing implications of production based models.
} 


\subsubsection{Financial markets}

There are two financial assets: a one-period riskless asset (government bonds), and a risky investment opportunity (capital stock). The riskless asset return is $R_{t}^{B}=\frac{1}{P_{t-1}^{B}}-1$, where $P^{B}$ denotes the government-bond price. The return on the risky asset is denoted by $R_{t}^{K}$. Before investing in stocks for the first time the investor must pay a fixed lump sum cost equal to $F P_{a}^{i} W_{t}$. This represents both the explicit transaction cost from opening a brokerage account and the (opportunity) cost of acquiring information about the stock market. The fixed cost $(F)$ is scaled by permanent labor income $\left(P_{a}^{i}\right)$ and by the aggregate wage $\left(W_{t}\right)$. This significantly simplifies the model's solution and is consistent with the opportunity cost interpretation.

\subsubsection{Wealth accumulation}

Total liquid wealth (cash-on-hand) can be consumed or invested in the two assets. At each age $(a)$, agents enter the period with wealth invested in the bond market, $B_{a}^{i}$, and (potentially) in stocks, $S_{a}^{i}$, and receive $L_{a}^{i} W_{t}$ as labor income. Let the dummy variable $I_{P}^{i}$ denote the time in which the participation cost is paid. Cash-on-hand at time $t$ is given by

$$
X_{a}^{i}=K_{a}^{i}\left(1+\left(1-\tau_{K}\right) R_{t}^{K}\right)+B_{a}^{i}\left(1+\left(1-\tau_{K}\right) R_{t}^{B}\right)+L_{a}^{i}\left(1-\tau_{s}\right) W_{t}-I_{P}^{i} F P_{a}^{i} W_{t}
$$

before retirement $\left(a<a^{R}\right)$, and by

$$
X_{a}^{i}=K_{a}^{i}\left(1+\left(1-\tau_{K}\right) R_{t}^{K}\right)+B_{a}^{i}\left(1+\left(1-\tau_{K}\right) R_{t}^{B}\right)+\lambda P_{a^{R}}^{i} W_{t}-I_{P}^{i} F P_{a^{K}}^{i} W_{t}
$$

during retirement $\left(a \geqslant a^{R}\right)$.

Households cannot borrow against their future labor income, and cannot short any asset. More precisely,

$$
\begin{aligned}
& B_{a}^{i} \geq 0 \\
& K_{a}^{i} \geq 0
\end{aligned}
$$




\subsection{The individual optimization problem}

\subsubsection{Household expectations}

Households are price takers and maximize utility given their expectations about future asset returns and aggregate wages. Under rational expectations, the latter are given by equations (4) and (5): future returns and wages are determined by future capital and labor, and by the realizations of aggregate shocks. Labor supply is exogenous as are the distributions of the aggregate shocks. The capital stock, however, is endogenous. Forming rational expectations of future returns and wages is, therefore, essentially equivalent to forecasting the future capital stock.

Capital accumulation is determined by the cross-sectional asset wealth distribution. We would therefore need to include this as a state-variable in the household's optimization problem. Krusell and Smith (1998) and den Haan (1997) suggest that, for this class of incomplete-markets economies, it is possible to approximate this infinite-dimensional state variable with a small set of moments. As discussed in the appendix, our model can accurately approximate the information contained in this distribution using its lagged mean (last-period's aggregate capital stock, $K_{t-1}$ ) and the state-contingent realizations of the two aggregate shocks (productivity shock, $U_{t}$, and stochastic depreciation, $\eta_{t}$ ):

$$
K_{t}=\Gamma_{K}\left(K_{t-1}, U_{t}, \eta_{t}\right)
$$

Since government bonds are only riskless over one period, households must forecast future bond prices $\left(P_{t}^{B}\right)$. The forecasting rule for $P_{t}^{B}$ is

$$
P_{t}^{B}=\Gamma_{P}\left(P_{t-1}^{B}, K_{t-1}, U_{t}, \eta_{t}\right)
$$

This introduces four additional state variables in the individual's maximization problem $\left(P_{t-1}^{B}, K_{t-1}, U_{t}\right.$, and $\left.\eta_{t}\right)$. 


\subsubsection{The dynamic programming problem}

We can now write the individual's recursive optimization problem. We normalize all individual variables by the household's permanent income $\left(P_{a}^{i} G_{t}^{\frac{1}{1-\alpha}}\right)$ and all aggregate variables (wage and capital) by aggregate permanent income $\left(G_{t}^{\frac{1}{1-\alpha}}\right)$. This induces stationarity in the model and reduces the dimensionality of the state vector by one variable. Normalized variables are denoted by lower case letters (i.e., $x_{a t}^{i} \equiv \frac{X_{a}^{i}}{P_{a}^{i} G_{t}^{1-\alpha}}, k_{t} \equiv \frac{K_{t}}{G_{t}^{1-\alpha}}$, and $w_{t} \equiv \frac{W_{t}}{G_{t}^{1-\alpha}}$ ). The value function is denoted by $V_{a}\left(x_{a t}^{i}, F_{a}^{i} ; k_{t}, U_{t}, \eta_{t}, P_{t}^{B}\right)$, where $a$ is age, $x_{a t}^{i}$ is individual normalized cash on hand, $F_{a}^{i}$ denotes the stock market participation status (a zero-one variable indicating whether the fixed cost has been paid or not), and the other four inputs are the aggregate variables from the forecasting equations $((16)$ and (17)). The individual optimization problem now becomes:

$$
\begin{aligned}
& V_{a}\left(x_{a t}^{i}, F_{a}^{i} ; k_{t}, U_{t}, \eta_{t}, P_{t}^{B}\right) \\
= & \underset{\left\{k_{a+1}^{i}, b_{a+1}^{i}\right\}_{a=1}^{A}}{\operatorname{Max}}\left\{\left(1-\beta p_{a}\right)\left(c_{a t}^{i}\right)^{1-1 / \psi}\right. \\
& \left.+\beta p_{a}\left(E_{t}\left[\left(\frac{P_{a+1}^{i}}{P_{a}^{i}}(1+g)^{\frac{1}{1-\alpha}}\right)^{1-\rho} V_{a+1}^{1-\rho}\left(x_{a+1, t+1}^{i}, F_{a+1}^{i} ; k_{t+1}, U_{t+1}, \eta_{t+1}, P_{t+1}^{B}\right)\right]\right)^{\frac{1-1 / \psi}{1-\rho}}\right\}^{\frac{1}{1-1 / \psi}}
\end{aligned}
$$

subject to the constraints,

$$
\begin{gathered}
k_{a+1}^{i} \geq 0 \\
b_{a+1}^{i} \geq 0 \\
c_{a}^{i}+b_{a+1}^{i}+k_{a+1}^{i}=x_{a}^{i}
\end{gathered}
$$

and with the laws of motion,

$$
\begin{gathered}
x_{a+1, t+1}^{i}=\frac{\left[k_{a+1}^{i}\left(1+\left(1-\tau_{K}\right) R_{t+1}^{K}\right)+b_{a+1}^{i}\left(1+\left(1-\tau_{K}\right) R_{t+1}^{B}\right)\right]}{\left[\left(P_{a+1}^{i} / P_{a}^{i}\right)(1+g)^{\frac{1}{1-\alpha}}\right]}+\varepsilon^{i}\left(1-\tau_{s}\right) w_{t+1}-I_{P}^{i} F w_{t+1} \\
R_{t+1}^{K}=R\left(k_{t+1}, U_{t+1}\right) \\
w_{t+1}=W\left(k_{t+1}, U_{t+1}\right) \\
k_{t+1}=\Gamma_{K}\left(k_{t}, U_{t+1}, \eta_{t+1}\right) \\
P_{t+1}^{B}=\Gamma_{P}\left(k_{t}, U_{t+1}, \eta_{t+1}, P_{t}^{B}\right)
\end{gathered}
$$




\subsection{Equilibrium}

The equilibrium consists of endogenously determined prices (bond prices, wages, and equity returns), a set of cohort specific value functions, and policy functions, $\left\{V_{a}, b_{a}, k_{a}\right\}_{a=1}^{A}$, and rational expectations about the evolution of the endogenously determined variables, such that:

1. Firms maximize profits by equating marginal products of capital and labor to their respective marginal costs: equations (4) and (5).

2. Individuals choose their optimal consumption and asset allocation by solving (18).

3. Markets clear and aggregate quantities result from individual decisions. Specifically,

$$
\begin{aligned}
& k_{t}=\int_{i} \int_{a} P_{a}^{i} k_{a t}^{i} d a d i \\
& b_{t}=\int_{i} \int_{a} P_{a}^{i} b_{a t}^{i} d a d i
\end{aligned}
$$

The aggregation equation for labor supply is redundant since there is no labor-leisure choice. Once these two equations are satisfied, Walras' law implies that total expenditure (government consumption, investment and household consumption) must equal total output:

$$
\frac{G C_{t}}{G_{t}^{\frac{1}{1-\alpha}}}+G_{t}^{\frac{1}{1-\alpha}} k_{t+1}-\left(1-\delta_{t}\right) k_{t}+\int_{i} \int_{a} P_{a}^{i} c_{a t}^{i} d a d i=U_{t} k_{t}^{\alpha} L_{t}^{1-\alpha}
$$

4. Accidental bequests $(E)$ are taxed at a $100 \%$ rate, and are given by:

$$
E_{t}=G_{t}^{\frac{1}{1-\alpha}} \int_{i} \int_{a}\left(1-p_{a}\right) P_{a}^{i} x_{a t}^{i} d a d i
$$

5. The social security system is balanced at all times,

$$
\int_{i} \int_{a \in I_{W}} \tau_{s} L_{a}^{i} w_{t} d a d i=\int_{i} \int_{a \in I_{R}}\left[\lambda \exp \left(f\left(a^{R}\right)\right) w_{t} P_{a^{R}}^{i}\right] d a d i
$$

where the left hand side is integrated over all workers $\left(a \in I_{W}\right)$, while the right hand side over retirees $\left(a \in I_{R}\right)$. We choose $\lambda$ exogenously, thereby endogenously determining the value of $\tau_{s}$ that keeps the social security system balanced in each period.

6. The government budget (equation (7)) is balanced every period to sustain a given ratio of government debt to $\operatorname{GDP}\left(b_{t} / y_{t}\right)$. 
7. Expectations about the future evolution of market prices (which depend on the wealth distribution) are verified in equilibrium.

Analytical solutions to this problem do not exist and we therefore use a numerical solution method (details are given in the appendix).

\subsection{Calibration}

\subsubsection{Aggregate variables}

Decisions are made at an annual frequency. The productivity shock follows a first-order Markov process with two values, $\left\{U^{b}, U^{g}\right\}$, where $U^{g}>U^{b}$. The probability of remaining in the current state $(\pi)$ is $2 / 3$, yielding an average business cycle duration of six years. The standard deviation of the aggregate productivity shock $\left(\sigma_{U}\right)$ is set to $1 \%$. Given all other parameter values, we set this volatility to match the standard deviation of aggregate output in the data.

Capital's share of output $(\alpha)$ is set to $36 \%$, and the average annual depreciation rate $(\delta)$ is $10 \%$. The parameter $s$ that determines the return volatility is set at $16 \%$. We discuss the calibration of $s$ (and $\sigma_{U}$ ) in much more detail below. The aggregate supply of bonds is set equal to $40 \%$ of GDP. The total value of U.S. government debt is actually higher, but a significant fraction is held by foreign institutions (or foreign governments). Our calibration is based on the average value of U.S. Treasury securities held by the U.S. public which is $35 \%$ of GDP, according to numbers from the Congressional Budget Office (from 1962 to 2003). We use $40 \%$ to take into account for additional indirect holdings (e.g. by corporations), which we cannot measure. The capital tax rate is $20 \%$, while bequests are taxed at $100 \% .^{12}$

\subsubsection{Household variables}

Agents begin working life at age 20, retire at age 65, and can live up to 100 years. We use the mortality tables of the National Center for Health Statistics to parameterize the conditional survival probabilities. The idiosyncratic shocks' variances are taken from Carroll (1992): 10 percent per year for $\sigma_{\varepsilon}$ and 8 percent per year for $\sigma_{\xi}$. The deterministic labor income

\footnotetext{
${ }^{12}$ Total bequest are quite small and this assumption is only made for simplicity.
} 
profile reflects the hump shape of earnings over the life-cycle. The corresponding parameter values, just like the retirement transfers $\left(\lambda=\left(1-\tau_{s}\right) 0.68\right)$, are taken from Cocco, Gomes and Maenhout (1999). From equation (31) this generates an endogenous social security tax $\left(\tau_{s}\right)$ of approximately $10 \%$.

We consider two cases for the fixed cost of participation: one where the cost is zero and another corresponding to $5 \%$ of the household's expected annual income. For the average household with an annual labor income of $\$ 35,000$, this corresponds to $\$ 1,750$. Paiella (2001) and Vissing-Jorgensen (2002b) have used Euler equation estimation methods to obtain implied participation costs from observed consumption choices. They find values in the $\$ 75$ to $\$ 200$ range, but these are per-period costs. Our number is therefore comparable in a present-value terms. Nevertheless, we show that we can also match the data with lower values of $F$ (e.g. $2.5 \%)$.

We consider two groups of agents with the same population size and different preference parameters. In the baseline version of the model, type- $A$ has low risk aversion $\left(\rho^{A}=1.5\right)$ and low elasticity of intertemporal substitution $\left(\psi^{A}=1 / 6\right)$, while type- $B$ has higher risk aversion $\left(\rho^{B}=5\right)$ and slightly higher elasticity of intertemporal substitution $\left(\psi^{B}=0.4\right)$. The discount factor $(\beta)$ is equal to 0.99 for both groups, corresponding to an average discount rate of $2.8 \%$ once adjusted for the survival probabilities.

\section{Baseline Results}

\subsection{Individual allocations}

\subsubsection{Consumption and savings}

Figure 1 plots the life-cycle profiles of consumption, wealth and labor income for the average household. From age 65 onwards labor income refers to retirement income. Early in life, households accumulate a small buffer-stock of wealth. Later on they start saving for

retirement. From about age 50 onwards consumption exceeds labor income, the difference being financed by the previously accumulated financial wealth. The combination of idiosyncratic shocks and preference heterogeneity induces significant cross-sectional heterogeneity 
in wealth accumulation. This is highlighted in Table 1 where we report the different quartiles of the wealth-to-income ratio distribution from the baseline model. For comparison, we include the same numbers from the 2001 SCF. The model's values are consistent with those in the data. In particular the model matches well the right tail of the wealth distribution. ${ }^{13}$

Early in life households face liquidity constraints and therefore they save only for precautionary reasons, i.e. to insure themselves against earnings shocks. As a result, at this life-cycle stage, savings are mostly determined by prudence/risk aversion $(\rho)$. The less riskaverse households accumulate less wealth since they are less concerned about background risk. At mid-life, the savings behavior is determined mostly by the preference for lowfrequency consumption smoothing, i.e. by the elasticity of intertemporal substitution (EIS, $\psi$ ). As a result, at this life-cycle stage households with lower EIS save less. Combining these two results, we conclude that type- $A$ households (with low $R A$ and low $E I S$ ) accumulate significantly less wealth over the life-cycle. On the contrary, the type- $B$ households (more risk-averse and with higher $E I S$ ) constitute the majority of the wealthy population.

\subsubsection{Participation rates}

Decreasing risk aversion increases the optimal share invested in stocks but, (as shown in the previous subsection) also decreases wealth accumulation at every life-cycle stage. The impact of a change in risk aversion on the participation decision will therefore depend on which of these two effects dominates. Consistent with life-cycle asset allocation models (e.g. Gomes and Michaelides (forthcoming)) we find that the wealth effect dominates. The stock market participation rate is much lower for the less-risk averse (type- $A$ ) households: 8.47\% versus $96.22 \%$ (see Table 2). Overall, the participation rate in the model is very close to the one in the data: $52.35 \%$ versus $51.94 \%$, respectively.

It is important to mention that our results do not depend on the fact that non-stockholders tend to have lower risk-aversion and/or lower EIS. As we discuss below, the preference parameters of the stock market non-participants are irrelevant for determining equilibrium asset pricing moments. What is crucial is that stock market non-participants are less wealthy

\footnotetext{
${ }^{13}$ We note however that, for higher percentiles (e.g. 90th or 95th), the values in the data are almost twice as high as those implied by the model.
} 
than the stock market participants. In the context of a life-cycle model with uninsurable labor income and retirement savings this implies some combination of lower risk aversion, lower EIS and lower discount rate. Naturally not all of these are simultaneously required. Here we choose the first two (lower risk aversion and lower EIS) and kept the discount rate identical, but we could have kept the EIS or risk aversion identical instead. All these alternative models would be observationally equivalent for our purposes.

\subsection{Asset prices and consumption volatility}

The model is calibrated to match the equity return volatility using the standard deviation of the stochastic depreciation $(s)$. We use the EIS of the type- $B$ agents $\left(\psi^{B}\right)$, and the discount factor $(\beta$, which is identical for both types) to match three key moments: the level and volatility of the riskless rate, and the consumption growth volatility (discussed below). We choose the preference parameters of the type- $A$ agents $(E I S$ and $R A$ ) to match the participation rate, which has almost no impact on asset pricing moments, as discussed in more detail in the next sections. This leaves one free parameter to match the risk premium: the type- $B$ agents' risk aversion. ${ }^{14}$

\subsubsection{Asset returns}

Table 3 reports the main asset pricing moments implied by the model, along with their empirical U.S. counterparts taken from Campbell (1999). The mean risk-free rate and the volatility of equity returns are closely matched. ${ }^{15}$ The standard deviation of the risk-free rate is $3.07 \%$ compared with $5.33 \%$ in the data. ${ }^{16}$ This result is particularly good since, in an economy with a non-trivial production sector, obtaining a low standard deviation of

\footnotetext{
${ }^{14}$ Since we have a model with incomplete markets this calibration is more complicated. For example, risk aversion also affects the risk-free rate, and the EIS also affects the risk premium. We discuss these relationships in more detail below.

${ }^{15}$ We could easily increase the volatility of equity returns to match the data exactly, by increasing $s$. Naturally the corresponding equity premium would be even higher with this alternative calibration. However, this would also lead to a higher volatility of both consumption growth and riskless rate.

${ }^{16}$ We undershot the risk-free rate volatility since we do not have inflation in the model.
} 
the riskless asset is quite challenging. Boldrin et al. (2001) report standard deviations between 17.4\% and 25.4\%, while Guvenen (2003) and Jermann (1998) obtain 5.7\% and $11.5 \%$, respectively. With a risk aversion coefficient of 5 for the type- $B$ agents, the implied equity premium is $4.33 \%$, corresponding to approximately $70 \%$ of the risk premium in the data. The serial correlation of equity returns is essentially zero as in the data, while the risk-free rate in the model is more persistent than its empirical counterpart.

\subsubsection{Consumption volatility}

In an equilibrium with limited participation, equity is priced by the stochastic discount factors of stockholders. Therefore, it is important to check that the consumption risk implied by the model is consistent with the data. Table 4 presents the standard deviation of consumption growth for both stockholders and non-stockholders. We compare these with the estimates in Vissing-Jørgensen (2002a), based on data from the Consumer Expenditure Survey (CES). ${ }^{17}$ Since consumption volatility in the CES slightly exceeds the volatility obtained from the NIPA numbers, we have calibrated the model to undershoot the estimates from Vissing-Jørgensen (2002a). With this in mind, the values in the model are similar to the ones in the data, with the volatility of consumption growth for stockholders being higher than that for non-stockholders.

\subsubsection{Correlation between labor income shocks and stock returns}

In a frictionless one-sector production economy the marginal productivity of capital and labor are both driven by the same productivity shock. The correlation between aggregate wages and the return on capital is therefore very high. This might suggest that our equity premium is driven by a counterfactually high correlation between household earnings shocks and stock returns. This is not the case, however. Consistent with the empirical evidence (e.g., Davis and Willen (2001)), the endogenous correlation between household-level labor income shocks and stock returns is close to zero (0.96\%). Two features of the model explain

\footnotetext{
${ }^{17}$ The numbers in Vissing-Jørgensen (2002a) are semi-annual. In table $I I I$ we convert them to an annual frequency by assuming i.i.d. consumption growth over six-month intervals (we multiply the six month standard deviations of consumption growth by $\sqrt{2}$ ).
} 
this. First, stochastic depreciation shocks $\left(\eta_{t}\right)$ reduce the correlation between stock returns $\left(R_{t}^{K}\right)$ and aggregate wages $\left(w_{t}\right)$, just as adjustment costs of capital would. Second, for a given correlation between $w_{t}$ and $R_{t}^{K}$, the idiosyncratic productivity shocks imply a much lower correlation between stock returns $\left(R_{t}^{K}\right)$ and household-level income $\left(H_{t}^{i}\right)$.

\section{Decomposing the Equity Premium}

In this section we explore the explanatory contribution to the equity premium of the four main features of the model: endogenous limited participation, preference heterogeneity, incomplete risk sharing among stockholders and positive bond supply.

\subsection{Limited participation}

\subsubsection{Model without limited participation}

We consider a version of the model with the stock market entry cost $(F)$ set to zero, keeping all other parameter values unchanged. The results are shown in Table 5 and are almost identical to those obtained for the baseline model. Most importantly, there is a very modest reduction in the equity premium: 5 basis points.

This might seem surprising given the results obtained in Saito (1995), Basak and Cuoco (1998), or Guvenen (2003). These papers argue that limited stock market participation can contribute for explaining the equity risk premium puzzle. In those models, however, stock market participation is exogenous, while we derive it endogenously. ${ }^{18}$ As a result, in our model the non-participants are significantly less wealthy than the rest of the population. This is consistent with the data. According to the latest numbers from the Survey of Consumer Finances, the participation rate is $88.84 \%$ among households with wealth above the median, and only $15.21 \%$ for those with wealth below the median. The median wealth for stockholders

\footnotetext{
${ }^{18}$ Heaton and Lucas (2000) and Polkovnichenko (2004) also have exogenous participation constraints, but they do not exclude a significant fraction of wealthy households. Therefore, their results are closer to ours. For example, in Heaton and Lucas (2000), changing the participation rate from $50 \%$ to $100 \%$ increases the equity premium by between $13 \%$ to $40 \%$ (depending on the specific parameter calibration).
} 
is $\$ 154,600$, while the median wealth for non-stockholders is $\$ 7,300$. In our model, the ratio of median stockholders' wealth to median non-stockholders' wealth is approximately 30. Therefore, excluding these households from the equity market has a negligible impact on the risk premium.

Only by assuming extremely high entry costs or by imposing the participation constraint exogenously, would it be possible to exclude rich households, thus producing a significant increase in the risk premium. More precisely, in Saito (1995), for parameter values that generate an equity premium in excess of $3 \%$, the shadow value of the fixed cost that would keep households out of the stock market ranges from $22.5 \%$ to $54.1 \%$ of total wealth. ${ }^{19}$

\subsubsection{Lower participation cost}

We also consider a lower fixed cost value $(F)$. As expected from our previous discussion, we can again match the participation decision if we re-calibrate the preference parameters of the type- $A$ agents. Moreover, this has almost no impact on the other aggregate variables. More precisely, we can decrease the fixed cost from $5 \%$ to $2.5 \%$, and still obtain a participation rate of $51.24 \%$ by reducing $\rho^{A}$ (the risk aversion of 'non-stockholders') to 1.2. All other variables remain essentially unchanged, and even the consumption growth of non-stockholders is only marginally affected.

Matching the participation rate with a lower entry cost makes our previous conclusion stronger: the stock market non-participants are now even less wealthy, and therefore excluding them from the stock market has a smaller impact on the equity premium. Only if we consider that our previous fixed cost value $(F=5 \%)$ is too low, could we question the conclusion that the participation constraint has almost no impact on asset prices.

\footnotetext{
${ }^{19}$ Since this cost is computed as a function of total wealth, the implied cost is even larger for the medianwealth household, when expressed in terms of current income (as we do in our model).
} 


\subsection{Preference heterogeneity}

\subsubsection{Baseline parameters}

We now consider an economy with only one type of agent: type- $B$, and the fixed cost of participation set to zero. All other parameter values remain the same as in the baseline case. We consider type- $B$ agents because we want to generate a meaningful high equity premium. We ignore the participation cost since it has almost no impact on these investors' behavior. The results are shown in column two of Table 6 . In column one we report the results for the two agent model without the fixed cost, for comparison. ${ }^{20}$

In the single-agent economy the (average) risk aversion is higher. This implies more wealth accumulation and a reduced average return on both assets. We find that the risk-free rate falls by more than the equity return and therefore the risk premium increases. The risk-free rate volatility decreases since the (average) EIS is also higher in the single-agent economy.

We must make two different comparisons for the standard deviation of consumption growth. First, it is higher than in the baseline economy. This is expected since now we do not have type $-A$ agents. The higher average risk aversion and higher average EIS both induce more wealth accumulation, and this increases the volatility of consumption growth. Second, when compared with the type- $B$ agents in the baseline model, consumption volatility has fallen. The preference parameters are now held constant and the risk-free rate volatility has decreased, allowing for better consumption smoothing.

\subsubsection{Re-calibrated model}

We re-calibrate the single agent economy to match the level of the riskless rate, while keeping the coefficient of relative risk aversion constant at 5. Since we have two "free" preference parameters (EIS , $\psi$, and discount rate, $\beta$ ) we could closely match the consumption volatility and the level of the riskless rate, as before. However, in an economy without limited participation it is not clear if total aggregate data or stockholders' data should be used to match the consumption volatility. We therefore match an intermediate value, by setting $\psi=0.35$

\footnotetext{
${ }^{20}$ These are essentially the same as the baseline results, as shown above (see table 3 ).
} 
and $\beta=0.97$. The results are shown in column three of Table 6 . The new economy shares most of the features of the previous single-agent economy (column two), in particular, a similar risk premium and a lower standard deviation of the risk-free rate.

Comparing these results with the ones obtained in the previous subsection we find that the two models deliver very similar implications for the aggregate variables. This implies that, if we do not care about matching participation rates, then we can simply use the model from this section (i.e. with one agent type only). However, as previously shown, if we also want to match participation, or generate a more realistic wealth distribution, then we must consider our baseline model. The economy without preference heterogeneity would require an extremely large fixed cost to deliver significant non-participation, and the implied wealth distribution does not replicate the lower half of the population.

\subsection{Incomplete risk sharing among stockholders}

We have shown that the equity premium in our model is not driven by limited participation. This contrasts with the results in Saito (1995), Basak and Cuoco (1998), or Guvenen (2003). However, in those models there is perfect risk sharing among stockholders, while in ours that is not the case. We have incomplete risk sharing because of the existence of aggregate uncertainty, which by definition cannot be fully diversified, and because of the presence of idiosyncratic shocks and liquidity constraints.

\subsubsection{Results without stochastic depreciation}

If we set both aggregate shocks equal to zero stocks and bonds become perfect substitutes. Therefore we only set $s$ equal to zero, and keep all other parameter values unchanged. The results are shown in Table 7 . The stock returns volatility is now close to zero, and the volatility of consumption growth also falls substantially: it is now $1.75 \%$ for stockholders and $0.81 \%$ for non-stockholders. ${ }^{21}$ Even though equity returns are almost riskless, the consumption growth volatility of stockholders and non-stockholders is not the same. These

\footnotetext{
${ }^{21}$ We still have non-stockholders even though stocks are almost riskless. Some households never accumulate enough wealth to justify the fixed cost payment, given the modest equity premium of $1.32 \%$.
} 
groups still have different ratios of financial wealth to labor income.

Despite the low volatility of returns (and consumption), we still obtain a $1.32 \%$ equity premium. The presence of undiversifiable idiosyncratic risk generates a high 'equilibrium market price of risk' thus delivering a non-trivial equity premium even for a smaller value of aggregate uncertainty. Given this market price of risk, the level of aggregate uncertainty essentially scales the risk premium up or down. ${ }^{22}$

It is interesting to report that, the correlation between labor income shocks and stock returns is now much higher: $57 \%$ versus $1 \%$ in the baseline case. This was expected since returns on capital are now driven exclusively by the aggregate productivity shock, just like wages. However, it is interesting to note that this correlation is still significantly below 1 , and this is due to the presence of the idiosyncratic productivity shocks.

\subsubsection{Calibration of aggregate uncertainty}

In standard endowment economies, aggregate consumption must equal aggregate dividends. Therefore, the consumption growth volatility is essentially an exogenous parameter that can be calibrated directly. In models with a non-linear production technology this is no longer the case. Based on our previous discussion we set the parameters $s$ and $\sigma_{u}$ to match the aggregate risk in the economy. For example, in the economy with low aggregate uncertainty (Table 7) the volatility of (stockholders') consumption growth is only $1.8 \%$ as opposed to $5.8 \%$ in the data, and $6.2 \%$ in our baseline economy.

The distinction between $s$ and $\sigma_{u}$ is important. With $\sigma_{u}$ alone (and $s=0$ ) we could match either the volatility of consumption (and output) or the stock return volatility, but not both simultaneously. In such a set-up, matching consumption volatility would produce a very low return volatility. On the other hand, matching the standard deviation of stock returns would imply a high standard deviation of consumption growth.

\footnotetext{
${ }^{22}$ This is the same mechanism that would obtain in the presence of explicit adjustment costs (e.g. Jermann (1998), Boldrin et al. (2001) or Guvenen (2003)) .
} 


\subsubsection{Correlation between the two aggregate shocks}

In the baseline case we have assumed that the two aggregate shocks (stochastic depreciation, $\eta_{t}$ and productivity, $U_{t}$ ) are independent. We now assume that they are positively correlated. This reflects higher capital utilization in booms and is motivated by the interpretation of $\delta_{t}$ as economic depreciation. As we increase this correlation we obtain the exact opposite results as from a small increase in the type- $B$ investors' EIS $\left(\psi^{B}\right) .{ }^{23}$ Therefore, the model with positive correlation between these two shocks is almost observationally equivalent to a model with independent shocks and a slightly lower value of $\psi^{B}$. For example, let $\kappa$ denote the probability of a high (low) $\eta_{t}$, conditional on a high (low) $U_{t}$. In the baseline model we have $\kappa=0.5$ and $\psi^{B}=0.4$. The corresponding results are very similar to those obtained with $\kappa=0.75$ and $\psi^{B}=0.375$.

\subsection{Level of government debt}

Asset pricing models usually assume that the riskless asset exists in zero net supply. This implies that the representative consumer must invest all of her wealth in the risky asset. In models with limited stock market participation, such as ours, this also implies that a significant fraction of the population must hold levered positions in equities. These predictions clearly contrast with the empirical evidence on household-level asset holdings (see, for instance, Poterba and Samwick (2001), Ameriks and Zeldes (2001), or Guiso, Haliassos and Japelli (2002)). We explicitly allow for government bonds in positive supply, and calibrate the model to match the historical ratio of government debt to GDP. However, this makes it harder to match the unconditional asset pricing moments. To show this, we decrease the ratio of government debt to GDP from $40 \%$ to $15 \%$ and compare the results with those obtained in the baseline economy. ${ }^{24}$

\footnotetext{
${ }^{23}$ Those results are discussed in the comparative statics section. The volatility of stock returns is almost unaffected, the standard deviation of stockholder's consumption growth and the equity premium increase, while the mean and standard deviation of bond returns decrease.

${ }^{24} \mathrm{We}$ do not consider a case with zero government debt because we still want to match the stock market participation rates. Since agents that do not participate in the stock market must hold positive amounts of bonds, the other agents would then be forced to hold negative amounts. Therefore, this would require
} 
We consider an economy with the same parameter values as in the baseline case. The results are shown in column two of Table 8. Naturally, as we decrease the bond supply, the bond price increases and the risk-free rate falls. Households are required to invest a larger fraction of their wealth in stocks. This leads to a higher equity premium and to a significant increase in the consumption growth volatility. More precisely, for the same parameter values as the baseline case, the risk-free rate drops to $-0.04 \%$ and the equity premium increases to $5.60 \%$, while the standard deviation of consumption growth for stockholders is now $5.72 \%$.

We now re-calibrate this version of the model to match the same asset pricing moments as the baseline case: mean riskless rate, participation rate, riskless rate volatility, and consumption growth volatility. Under the new calibration we decreased the discount factor $(\beta)$ to 0.98 . The results are shown in column three of Table 8. With a consumption volatility (for stockholders) of $5.23 \%$ and a riskless rate of $1.35 \%$, the model generates an equity premium of $5.23 \%$. Therefore, as we converge to the standard assumption (zero bond net supply), the equity premium in the model approaches the historical value.

\section{Additional Comparative Statics}

\subsection{Preference parameters}

Table 9 reports changes in key moments of the model from perturbing the main preference parameters. There is no change in the standard deviation of equity returns (therefore not reported) because stock market volatility is determined almost exclusively by stochastic depreciation $(s)$.

Decreasing $\psi^{B}$ (the type- $B$ investors' $E I S$ ) or decreasing $\beta$ (the discount factor) produces similar results. In both cases there is a reduction in wealth accumulation $(K / Y$ falls) implying an increase in the average returns of both assets. The supply of the riskless asset is constant while the capital stock is endogenous. Market clearing therefore implies that the risk-free rate increases by more than the return on capital. Hence, in equilibrium, the equity premium falls. The stockholders' consumption growth volatility decreases slightly since

relaxing the short-selling constraints on equity, making it harder to compare across the two cases. 
there is a reduction in the ratio of financial wealth to labor income. Naturally, changing the discount factor also significantly impacts the volatility of non-stockholders consumption growth, since this parameter has the same value for both types.

As we decrease the type- $B$ investors' risk aversion $\left(\rho^{B}\right)$, we have two effects on returns. First, total wealth accumulation falls leading to an increase in the average returns on both assets. Second, these investors are now more willing to hold equity, which simultaneously increases the risk-free rate and decreases the expected return on capital. These two effects lead to a clear increase in the risk-free rate. In addition, we should observe a larger decrease in the equity premium than in the previous experiments (i.e. when decreasing $\psi^{B}$ or $\beta$ ). The impact on the capital stock and the expected equity return, however, is ambiguous. For these parameter values, the capital output ratio decreases slightly thus increasing the equity return. The standard deviation of stockholders' consumption growth falls, again due to a reduction in the ratio of financial wealth to labor income. ${ }^{25}$

Finally, the participation rate is almost unaffected in all cases. Stock market participation is essentially determined by the fixed cost and the preference parameters of the type- $A$ investors.

\subsection{Other parameters}

In Table 10 we present comparative statics on the technology parameters. An increase in $\sigma_{U}$ is reflected in higher volatility of output (not reported) and consumption. As aggregate uncertainty increases so does precautionary savings. Consequently, the capital-output ratio increases and asset returns fall. Since bond supply is constant the riskless rate must adjust more than the return on capital, leading to a modest increase in the equity premium. A higher $\pi$ (persistence of $U$ ) also increases aggregate uncertainty by increasing the persistence of the transitory shocks. The qualitative results are, therefore, the same as the ones obtained in the previous experiment (higher $\sigma_{U}$ ). Since these shocks are transitory the quantitative

\footnotetext{
${ }^{25}$ The standard deviation of non-stockholders consumption growth is also marginally affected for two reasons. First, there is the indirect impact on the type- $A$ investors (most of whom are non-stockholders) through the change on the level and volatility of the risk-free rate. Second, some of the type- $B$ investors are also non-stockholders.
} 
impact is small.

A lower depreciation rate $(\delta)$ makes equity relatively more attractive, causing the capital stock to increase substantially. Mechanically, a $2 \%$ reduction in $\delta$ would lead to an equal increase in the average return on capital. However, since the capital stock is also higher, the equilibrium average equity return only increases by $0.76 \%$. The risk-free rate also rises, reflecting the change in the relative demand for the two assets.

\section{Conclusion}

We present an asset pricing model with incomplete markets and heterogeneous agents that reproduces key aggregate moments, while being consistent with observed individual asset allocation decisions. More precisely, the model matches the level and volatility of the riskfree rate, the stock market participation rate and the micro-evidence on asset allocation decisions. Further, the model explains approximately two thirds of the historical equity risk premium.

Market incompleteness results from both aggregate and (uninsurable) idiosyncratic shocks. The idiosyncratic uncertainty is driven by a (realistically) calibrated life-cycle income profile that agents cannot fully insure, and against which they cannot borrow. This is a very important feature of the model. If we want to closely replicate the level of risk that households actually face, then an infinite horizon model (without a retirement period among other things) would fall short.

We then decompose each component's contribution to the risk premium. We find that limited stock market participation has a negligible impact, contrary to previous results in the literature where the participation decision is specified exogenously. The risk premium in our model is generated by incomplete risk sharing among stockholders. Furthermore, accounting for government bonds in positive supply drives down the equity premium, making it harder to match the historical numbers. If we relax this assumption, the model is able to match the historical equity premium with a realistic consumption growth volatility.

One should be careful about interpreting our limited participation results. Namely, these results do not imply that all changes in the participation rate will have (close to) zero impact 
on asset prices. In particular, a social security reform that changes households' savings incentives (or creates forced savings), will simultaneously increase the participation rate and the wealth accumulation by (the previous) non-stockholders. Equilibrium returns could then be significantly affected. Our results do, however, imply that reductions in the transaction costs associated with stock market participation (e.g. reduction in brokerage fees, expansion of online discount brokers, etc.) will have almost no impact on the steady-state distribution of asset returns. 


\section{Appendix: Solving the model}

1) Solution method outline

The solution method builds on den Haan (1994, 1997), Krusell and Smith $(1997,1998)$ and Storesletten et al. (2001). We start by presenting the outer loop of the code and discuss the details afterwards.

The numerical sequence works as follows:

i) Specify a set of forecasting equations $\left(\Gamma_{K}\right.$ and $\left.\Gamma_{P}\right)$.

ii) Solve the household's decision problem, taking prices as given, and using the forecasting equations to form expectations (details in 2).

iii) Given the policy functions, simulate the model (5500 periods) while computing the market clearing variables at each period (details in 3 ).

iv) Use the simulated time-series to update the forecasting equations (details in 4).

v) Repeat ii), iii) and iv) with the new forecasting equations until convergence. We have two convergence criteria:

- Stable coefficients in the forecasting equations.

- Forecasting equations with regression $R^{2}$ above $99 \%$.

\section{2) Solving the household's decision problem}

2.1) Normalization

We first simplify the solution by exploiting the scale-independence of the maximization problem and rewriting all individual variables as ratios to the permanent component of labor income $\left(P_{a}^{i}\right)$ and of the deterministic growth $\left(G^{\frac{1}{1-\alpha}}\right)$. Likewise all aggregate variables (the wage and capital) are normalized by $G_{t}^{\frac{1}{1-\alpha}}$ thus inducing stationarity in the model. Using lower case letters to denote the normalized variables we have, for instance

$$
\begin{gathered}
x_{a t}^{i} \equiv \frac{X_{a}^{i}}{P_{a}^{i} G_{t}^{\frac{1}{1-\alpha}}} \\
k_{t} \equiv \frac{K_{t}}{G_{t}^{\frac{1}{1-\alpha}}}, \quad w_{t} \equiv \frac{W_{t}}{G_{t}^{\frac{1}{1-\alpha}}}
\end{gathered}
$$

The equations of motion and the value function can then be rewritten as normalized variables, allowing us to reduce the number of state variables. The normalized individual cash on hand 
state variable follows

$$
x_{a+1, t+1}^{i}=\frac{\left[k_{a+1}^{i}\left(1+\left(1-\tau_{K}\right) R_{t+1}^{K}\right)+b_{a+1}^{i}\left(1+\left(1-\tau_{K}\right) R_{t+1}^{B}\right)\right]}{[G R]}+\varepsilon^{i}\left(1-\tau_{s}\right) w_{t+1}-I_{P}^{i} F w_{t+1}
$$

where $G R=\frac{P_{a+1}^{i}}{P_{a}^{i}}(1+g)^{\frac{1}{1-\alpha}}$, and the value function becomes $V_{a}\left(x_{a t}^{i}, F_{a}^{i} ; k_{t}, U_{t}, \eta_{t}, P_{t}^{B}\right)$.

1. The rates of return on the factors of production can be written as

$$
R_{t}^{K}=\alpha Z_{t}\left(\frac{K_{t}}{L_{t}}\right)^{\alpha-1}-\delta_{t}=\alpha Z_{t}\left(\frac{k_{t} G_{t}^{\frac{1}{1-\alpha}}}{L_{t}}\right)^{\alpha-1}-\delta_{t}=\alpha U_{t}\left(\frac{k_{t}}{L_{t}}\right)^{\alpha-1}-\delta_{t}
$$

and

$$
W_{t}=(1-\alpha) Z_{t}\left(\frac{k_{t}}{L_{t}}\right)^{\alpha}=(1-\alpha) G_{t}^{\frac{1}{1-\alpha}} U_{t}\left(\frac{k_{t}}{L_{t}}\right)^{\alpha}
$$

so that $w_{t}=(1-\alpha) U_{t}\left(\frac{k_{t}}{L_{t}}\right)^{\alpha}$.

\section{2) Discretization of the state space}

Age $(a)$ is a discrete state variable taking 81 possible values. We discretize the cash-onhand dimension $\left(x_{t}^{i}\right)$ using 51 points, with denser grids closer to zero to take into account the higher curvature of the value function in this region. With respect to the other two continuous state variables, we use 16 points to discretize $k_{t}$, and 25 points to discretize $P_{t}^{B}$. The remaining state variables, depreciation shock $\left(\eta_{t}\right)$, aggregate productivity shock $\left(U_{t}\right)$ and participation status $\left(F_{t}^{i}\right)$ are all discrete, each taking only two possible values. Therefore no approximation is required. ${ }^{26}$

The grid range for the continuous state variables is verified ex-post by comparing with the values obtained in the simulations, and with the results obtained when this range is increased. The number of grid points for $x_{t}$ is particularly important for producing an accurate participation decision, since the policy functions for consumption and asset allocation would not require this many points. A smaller number of grid points for $k_{t}$ and for $P_{t}^{B}$ would not affect the policy functions directly. It would, however, affect the R-squared of the forecasting equations and the convergence of their respective coefficients.

\section{3) Maximization}

\footnotetext{
${ }^{26}$ In the baseline version of the model this leads to a state space of dimension 13, 219, 200.
} 
We solve the maximization problem for each agent type using backward induction. For every age $a$ prior to $A$, and for each point in the state space, we optimize using grid search. We need to compute the value associated with each set of controls (consumption, decision to pay the fixed cost, and share of wealth invested in stocks). From the Bellman equation,

$$
\begin{aligned}
& V_{a}\left(x_{a t}^{i}, F_{a}^{i} ; k_{t}, U_{t}, \eta_{t}, P_{t}^{B}\right) \\
= & \underset{\left\{k_{a+1}^{i}, b_{a+1}^{i}\right\}_{a=1}^{A}}{\operatorname{Max}}\left\{\left(1-\beta p_{a}\right)\left(c_{a t}^{i}\right)^{1-1 / \psi}\right. \\
& \left.+\beta p_{a}\left(E_{t}\left[\left(\frac{P_{a+1}^{i}}{P_{a}^{i}}(1+g)^{\frac{1}{1-\alpha}}\right)^{1-\rho} V_{a+1}^{1-\rho}\left(x_{a+1, t+1}^{i}, F_{a+1}^{i} ; k_{t+1}, U_{t+1}, \eta_{t+1}, P_{t+1}^{B}\right)\right]\right)^{\frac{1-1 / \psi}{1-\rho}}\right\}^{\frac{1}{1-1 / \psi}}
\end{aligned}
$$

these values are given as a weighted sum of current utility $\left(\left(c_{a t}^{i}\right)^{1-1 / \psi}\right)$ and the expected continuation value $\left(E_{a} V_{a+1}().\right)$, which we can compute once we have obtained $V_{a+1}$. In the last period, regardless of whether the fixed cost has already been paid, the policy functions are trivial and the value function corresponds to the indirect utility function. This gives us the terminal condition for our backward induction procedure. Once we have computed the value of all the alternatives we pick the maximum, thus obtaining the policy rules for the current period. Substituting these decision rules in the Bellman equation we obtain this period's value function $\left(V_{a}().\right)$, which is then used to solve the previous period's maximization problem. This process is iterated until $a=1$.

We use the forecasting equations $\left(\Gamma_{K}\right.$ and $\left.\Gamma_{P}\right)$ to form expectations of the aggregate variables, and we perform all numerical integrations using Gaussian quadrature to approximate the distributions of the innovations to the labor income process $\left(\varepsilon^{i}\right.$ and $\left.\xi^{i}\right)$ and the aggregate shocks $\left(\eta_{t}\right.$ and $\left.U_{t}\right)$. For points which do not lie on state space grid, we evaluate the value function using a cubic spline interpolation along the cash-on-hand dimension, and a bi-linear interpolation along the other two continuous state variables $\left(k_{t}\right.$ and $\left.P_{t}^{B}\right)$. Bi-linear interpolation works well along these two dimensions because households are price takers, and therefore these state variables are not affected by the control variables.

\section{3) Simulating the model and clearing markets}

\section{1) Simulation}

We use the policy functions for the two agent types $(A$ and $B)$ to simulate the behavior of 2000 agents of each type in each of the 81 cohorts (total of 324,000 households) over 5500 
periods. The realizations of the aggregate random variables (stochastic depreciation $\eta_{t}$ and aggregate productivity $U_{t}$ ) are drawn from their original two-point distributions, while the idiosyncratic productivity shocks $\left(\varepsilon^{i}\right.$ and $\left.\xi^{i}\right)$ are drawn from the corresponding log-normal distributions. All other random variables are endogenous to the model. The realizations of the exogenous random variables are held constant within the outer loop, i.e. across iterations, so as not to affect the convergence criteria.

3.2) Market clearing

For every time period we simulate the households' behavior for every possible bond price (i.e. every point in the grid for $P_{t}^{B}$ ). We then aggregate the individual bond demands and use a linear interpolation to determine the market clearing bond price. All household equilibrium allocations (consumption and asset holdings) are then obtained from a linear interpolation with the same coefficients, while the aggregate variables (capital and output) are computed by aggregating these market clearing allocations. This then determines the state variables for simulating the next period's decisions.

\section{4) Updating the forecasting equations:}

Using the simulated time-series (after discarding the first 500 observations) we estimate the following OLS regressions, for every pair of productivity shock $\left(U_{t+1}\right)$ and depreciation shock $\left(\eta_{t+1}\right)$ realizations,

$$
\ln \left(k_{t+1}\right)=q_{10}+q_{11} \ln \left(k_{t}\right)
$$

and

$$
\ln \left(P_{t+1}^{B}\right)=q_{20}+q_{21} \ln \left(k_{t}\right)+q_{22} \ln \left(P_{t}^{B}\right)+q_{23}\left(\ln \left(P_{t}^{B}\right)\right)^{2}
$$

This gives us 8 equations and 8 sets of coefficients that forecast state-contingent capital $\left(k_{t+1}\right)$ and bond price $\left(P_{t+1}^{B}\right)$. We iterate the code until we have converged on the coefficients and on the R-squared of these regressions. For the first set of equations (A7) we obtain Rsquared values around $99.99 \%$. For the second set of equations (A8), the R-squared values are in the $90 \%-95 \%$ range when we only use $\ln \left(k_{t}\right)$ as a regressor, increase to about $99 \%$ when we add $\ln \left(P_{t}^{B}\right)$, and are all above this threshold once we add the squared term: $\left(\ln \left(P_{t}^{B}\right)\right)^{2}$. 


\section{References}

Abel, Andrew, 2001, The Effects of Investing Social Security Funds in the Stock Market When Fixed Costs Prevent Some Households from Holding Stocks, American Economic Review, 91, 128-148.

Abel, Andrew, and Janice Eberly, 1994, A Unified Model of Investment Under Uncertainty, American Economic Review, 84, 5, 1369-1384.

Aiyagari, Rao, and Mark Gertler, 1991, Asset Returns With Transactions Costs and Uninsured Individual Risk, Journal of Monetary Economics 27, 311-31.

Allen, Franklin and Douglas Gale, 1994, Limited Market Participation and Volatility of Asset Prices, American Economic Review 84, 933-955.

Ameriks, John, and Stephen Zeldes, 2001, How Do Household Portfolio Shares Vary With Age?, Working Paper, Columbia Business School.

Attanasio, Orazio, James Banks, and Sarah Tanner, 2002, Asset Holding and Consumption Volatility, Journal of Political Economy 110, 771-92.

Basak, Suleyman, and Domenico Cuoco, 1998, An Equilibrium Model with Restricted Stock Market Participation, Review of Financial Studies 11, 309-41.

Bertaut, Carol, and Michael Haliassos, 1997, Precautionary Portfolio Behavior from a Life Cycle Perspective, Journal of Economic Dynamics and Control 21, 1511-1542.

Benzoni, Luca, Pierre Collin-Dufresne and Robert S. Goldstein, 2004, Portfolio Choice over the Life-Cycle in the Presence of 'Trickle Down' Labor Income, Working Paper, Carnegie Mellon University.

Boldrin, Michael, Larry Christiano, and Jonas Fisher, 2001, Habit Persistence, Asset Returns and the Business Cycle, American Economic Review 91, 149-166.

Brav, Alon, George Constantinides, and Christopher Geczy. 2002. Asset Pricing with Heterogeneous Consumers and Limited Participation: Empirical Evidence, Journal of Political Economy, 110(4): 793-824.

Calvet, Laurent, Martin Gonzalez-Eiras, and Paolo Sodini. 2002. Financial Innovation, Market Participation and Asset Prices, Working Paper, Harvard University.

Campbell, John, 1999, Asset Prices, Consumption and the Business Cycle, Chapter 19 
in Handbook of Macroeconomics, John Taylor and Michael Woodford eds., North-Holland.

Campbell, John, and John Cochrane, 1999, By Force of Habit: A Consumption-Based Explanation of Aggregate Stock Market Behavior, Journal of Political Economy, 107, 205251.

Campbell, John, Joao Cocco, Francisco Gomes, and Pascal Maenhout, 2001, Investing Retirement Wealth: A Life Cycle Model, In Risk Aspects of Social Security Reform (The University of Chicago Press).

Cao, Henry, Tan Wang, and Harold Zhang, Model Uncertainty, Limited Market Participation and Asset Prices, Review of Financial Studies, forthcoming.

Carroll, Christopher, 1992, The Buffer-Stock Theory of Saving: Some Macroeconomic Evidence, Brookings Papers on Economic Activity 2: 61-156.

Cocco, Joao, Portfolio Choice in the Presence of Housing, Review of Financial Studies, forthcoming.

Cocco, Joao, Francisco Gomes, and Pascal Maenhout, 1999, Portfolio Choice Over The Life Cycle, Working Paper, Harvard University.

Cochrane, John, 1991, Production-Based Asset Pricing and the Link Between Stock Returns and Economic Fluctuations, Journal of Finance, 46, 207-234.

Constantinides, George, John Donaldson, and Rajnish Mehra, 2002, Junior Can’t Borrow: A New Perspective on the Equity Premium Puzzle, Quarterly Journal of Economics 117, 269-96.

Dammon, Robert, Chester Spatt, and Harold Zhang, 2001, Optimal Consumption and Investment with Capital Gains Taxes, Review of Financial Studies 14, 583-616.

Davis, Steven, and Paul Willen, 2001, Occupation-level Income Shocks and Asset Returns: Their Covariance and Implications for Portfolio Choice, Working Paper, University of Chicago.

Davis, Steven, Felix Kubler, and Paul Willen, 2002, Borrowing Costs and the Demand for Equity over the Life Cycle, Working Paper, University of Chicago and Stanford University.

Deaton, Angus, 1991, Saving and Liquidity Constraints, Econometrica 59, 1221-48.

den Haan, Wouter, 1994, Heterogeneity, Aggregate Uncertainty and the Short-Term Interest Rate, Journal of Business and Economic Statistics, 14, 399-411. 
den Haan, Wouter, 1997, Solving Dynamic Models with Aggregate Shocks and Heterogenous Agents, Macroeconomic Dynamics, 1, 355-386.

Eberly, Janice, 1997, International Evidence on Investment and Fundamentals, European Economic Review, 41, 1055-1078.

Epstein, Lawrence, and Stanley Zin, 1989, Substitution, Risk Aversion, and the Temporal Behavior of Consumption and Asset Returns: A Theoretical Framework, Econometrica 57, 937-969.

Gomes, Francisco, and Alexander Michaelides, 2003, Portfolio Choice with Internal Habit Formation: A life cycle Model with Uninsurable Labor Income Risk, Review of Economic Dynamics 6, 729-766.

Gomes, Francisco, and Alexander Michaelides, Optimal Life-Cycle Asset Allocation: Understanding the Empirical Evidence, Journal of Finance, forthcoming.

Gottardi, Piero, and Felix Kubler, 2004, Ex Ante Optimality and Social Security, Working Paper, University of Venice and Stanford University.

Greenwood, J., Z. Hercowitz and G. Huffman, 1988, Investment, Capacity Utilization and the Business Cycle, American Economic Review, 78, 402-418.

Greenwood, J., Z. Hercowitz and P. Krusell, 1997, Long-Run Implications of InvestmentSpecific Technological Change, American Economic Review, 87, 342-362.

Grossman, S. and O. Hart, 1979, A Theory of Competitive Equilibrium in Stock Market Economies, Econometrica, 47, 293-329.

Guiso, Luigi, Michael Haliassos, and Tullio Japelli, 2002, Household Portfolios: An International Comparison, in Household Portfolios, eds, Luigi Guiso, Michael Haliassos and Tullio Japelli, MIT Press.

Guvenen, Fatih, 2003, A Parsimonious Macroeconomic Model for Asset Pricing: Habit Formation or Cross-Sectional Heterogeneity. Working paper, University of Rochester.

Haliassos, Michael and Alexander Michaelides, 2003, "Portfolio Choice and Liquidity Constraints," International Economic Review, 44 (1): 143-77.

He, Hua, and David Modest, 1995, Market Frictions and Consumption-Based Asset Pricing, Journal of Political Economy 103, 94-117.

Heaton, John, and Deborah Lucas, 1996, Evaluating the Effects of Incomplete Markets 
on Risk Sharing and Asset Pricing, Journal of Political Economy 104, 443-87.

Heaton, John, and Deborah Lucas, 1997, Market Frictions, Savings Behavior, and Portfolio Choice, Macroeconomic Dynamics 1, 76-101.

Heaton, John, and Deborah Lucas, 2000, Stock Prices and Fundamentals, NBER Macroeconomics Annual 14, 213-42.

Hercowitz, Zvi, 1986, The Real Interest Rate and Aggregate Supply, Journal of Monetary Economics 18, 121-145.

Hu, Xiaoqing, 2001, Portfolio Choices for Home Owners, Working Paper, University of Illinois at Chicago.

Jermann, Urban, 1998, Asset Pricing in Production Economies, Journal of Monetary Economics, 41, 257-275.

Koo, Hyeng, 1998, Consumption and Portfolio Selection with Labor Income: A Continuous Time Approach, Mathematical Finance 8, 49-65.

Krueger, Dirk, and Felix Kubler, 2004, Intergenerational Risk sharing via Social Security when Financial Markets are Imcomplete, Working Paper, University of Pennsylvania.

Krusell, Per, and Anthony Smith, 1997, Income and Wealth Heterogeneity, Portfolio Choice, and Equilibrium Asset Returns, Macroeconomic Dynamics, 1, 387-422.

Krusell, Per, and Anthony Smith, 1998, Income and Wealth Heterogeneity in the Macroeconomy, Journal of Political Economy, 106, 867-896.

Lettau, Martin, 2003, Inspecting the Mechanism: Closed-Form Solutions for Asset Prices in Real Business Cycle Models, Economic Journal 113 (489), 550-575.

Lucas, Deborah, 1994, Asset Pricing with Undiversifiable Risk and Short Sales Constraints: Deepening the Equity Premium Puzzle, Journal of Monetary Economics 34, 32541.

Luttmer, Erzo, 1999, What Level of Fixed Costs Can Reconcile Consumption and Stock Returns?, Journal of Political Economy 107, 969-97.

Mankiw, N. Gregory, and Stephen Zeldes, 1991, The Consumption of Stockholders and Non-Stockholders, Journal of Financial Economics 29, 97-112.

Paiella, Monica, 2001, Transaction Costs and Limited Stock Market Participation to Reconcile Asset Prices and Consumption Choices, IFS Working Paper 01/06. 
Polkovnichenko, Valery, 2002, Life Cycle Consumption and Portfolio Choice with Additive Habit Formation Preferences and Uninsurable Labor Income Risk, Working Paper, University of Minnesota.

Polkovnichenko, Valery, 2004, Limited Stock Market Participation and the Equity Premium, Finance Research Letters, 1, 24-34.

Poterba, James, and Andrew Samwick, 2001, Portfolio Allocations over the Life Cycle, in Seiritsu Ogura, Toshiaki Tachibanaki, and A. David Wise (eds.) Aging Issues in the United States and Japan. University of Chicago Press.

Saito, Makoto, 1995, Limited Market Participation and Asset Pricing, Working Paper, University of British Columbia.

Storesletten, Kjetil, Chris Telmer, and Amir Yaron, 2001, Asset Pricing with Idiosyncratic Risk and Overlapping Generations,Working Paper, Carnegie Mellon University.

Telmer, Chris, 1993, Asset-Pricing Puzzles and Incomplete Markets, Journal of Finance 48, 1803-32.

Viceira, Luis, 2001, Optimal Portfolio Choice for Long-Horizon Investors with Nontradable Labor Income, Journal of Finance 55, 1163-98.

Vissing-Jørgensen, Annette, 2002a, Limited Asset Market Participation and the Elasticity of Intertemporal Substitution, Journal of Political Economy 110, 825-53.

Vissing-Jørgensen, Annette, 2002b, Towards an Explanation of Household Portfolio Choice Heterogeneity: Nonfinancial Income and Participation Cost Structures, Working paper, Northwestern University.

Yao, Rui, and Harold Zhang, Optimal Consumption and Portfolio Choices with Risky Housing and Borrowing Constraints, Review of Financial Studies, forthcoming. 
Table 1: Moments from the wealth-to-income ratio distribution.

The table reports values from the baseline model and the data (2001 Survey of Consumer Finances). Income is defined as the sum of wages and salaries, unemployment or worker's compensation and pensions, annuities, or other disability or retirement programs. Wealth is defined as liquid assets plus home equity. Liquid wealth is made up of all types of transaction accounts, certificates of deposit, total directly-held mutual funds, stocks, bonds, total quasiliquid financial assets, savings bonds, the cash value of whole life insurance, other managed assets (trusts, annuities and managed investment accounts) and other financial assets. Home equity is defined as the value of the home less the amount still owed on the first and 2nd/3rd mortgages and the amount owed on home equity lines of credit.

\begin{tabular}{|c|c|c|}
\hline & Model & Data \\
\hline 25th percentile & 1.09 & 0.33 \\
\hline Median & 2.87 & 1.75 \\
\hline 75th percentile & 5.42 & 5.25 \\
\hline
\end{tabular}

Table 2: Stock market participation rates $(\bar{P})$.

The second row reports data from the 2001 Survey of Consumer Finances; the third row reports the unconditional results from baseline model; the fourth and fifth rows report the average participation rates for each type of agent. Type- $A$ agents have risk aversion equal to 1.5, and elasticity of intermporal substitution equal to $1 / 6$, and type- $B$ agents have risk aversion equal to 5 and elasticity of intertemporal substitution equal to 0.4 .

\begin{tabular}{|c|c|}
\hline & $\bar{P}$ \\
\hline Data & $51.94 \%$ \\
\hline Model (average) & $52.35 \%$ \\
\hline Model (Type- $A$ ) & $8.47 \%$ \\
\hline Model (Type- $B$ ) & $96.22 \%$ \\
\hline
\end{tabular}


Table 3: Asset pricing moments from the data (Campbell (1999)) and from the baseline model.

\begin{tabular}{|c|c|c|c|}
\hline Variable & Moment & Model & Data \\
\hline Risk-free Rate & Mean & $1.72 \%$ & $1.58 \%$ \\
& Std. Dev. & $3.07 \%$ & $5.33 \%$ \\
& $\mathrm{AR}(1)$ & 0.88 & 0.52 \\
\hline Equity Return & Mean & $6.05 \%$ & $8.31 \%$ \\
& Std. Dev. & $16.31 \%$ & $19.81 \%$ \\
& $\mathrm{AR}(1)$ & -0.05 & -0.06 \\
\hline Risk Premium & Mean & $4.33 \%$ & $6.74 \%$ \\
\hline
\end{tabular}

Table 4: Consumption volatility.

The second row reports the standard deviation of stockholders' consumption growth from the baseline model and from the data (Consumer Expenditure Survey, numbers taken from Vissing-Jørgensen (2002a) and annualized). The third row reports the same statistics for nonstockholders' consumption growth.

\begin{tabular}{|c|c|c|c|}
\hline Variable & Moment & Model & Data \\
\hline Cons.Growth (S) & Std. Dev. & $4.91 \%$ & $5.80 \%$ \\
Cons.Growth (NS) & Std. Dev. & $2.32 \%$ & $3.96 \%$ \\
\hline
\end{tabular}


Table 5: Asset pricing moments from the data (Campbell (1999)) and from the model with different values of the fixed entry cost $(F)$.

\begin{tabular}{|c|c|c|c|c|}
\hline Variable & Moment & $F=0.05$ & $F=0.00$ & Data \\
\hline Riskless Rate & Mean & $1.72 \%$ & $1.70 \%$ & $1.58 \%$ \\
& Std. Dev. & $3.07 \%$ & $3.04 \%$ & $5.33 \%$ \\
& AR(1) & 0.88 & 0.88 & 0.52 \\
\hline Equity Return & Mean & $6.05 \%$ & $5.98 \%$ & $8.31 \%$ \\
& Std. Dev. & $16.31 \%$ & $16.30 \%$ & $19.81 \%$ \\
& AR(1) & -0.05 & -0.05 & -0.06 \\
\hline Risk Premium & Mean & $4.33 \%$ & $4.28 \%$ & $6.74 \%$ \\
\hline
\end{tabular}


Table 6: Asset pricing and consumption moments from the data and from different versions of the model, without the fixed cost of participation $(F=0)$.

The asset pricing data is taken from Campbell (1999) while the consumption data is from Vissing-Jørgensen (2002a). The results from the model are reported in columns one through three. Column one ("Two types") shows the results for the baseline calibration (with $F=0$ ). Column two ("One type (i)") refers to the case in which only the type- $B$ agents exist in the economy, with all other parameter values identical to the ones in the baseline economy. In column three ("One type (ii)"), we re-calibrate the preference parameters of the single-agent. More precisely we set $\psi=0.35$ and $\beta=0.97$. Rows 1 through 7 report the same asset pricing moments as in the baseline case. Row 8 reports the standard deviation of consumption growth. For comparison, in the case of the economy with two types of agents we show the value for the type- $B$ agents.

\begin{tabular}{|c|c|c|c|c|c|}
\hline Variable & Moment & Two types & One type (i) & One type (ii) & Data \\
\hline Riskless Rate & Mean & $1.70 \%$ & $-2.69 \%$ & $0.75 \%$ & $1.58 \%$ \\
& Std. Dev. & $3.04 \%$ & $2.31 \%$ & $2.60 \%$ & $5.33 \%$ \\
& AR(1) & 0.88 & 0.86 & 0.88 & 0.52 \\
\hline Equity Return & Mean & $5.98 \%$ & $1.33 \%$ & $4.94 \%$ & $8.31 \%$ \\
& Std. Dev. & $16.30 \%$ & $16.22 \%$ & $16.28 \%$ & $19.81 \%$ \\
& AR(1) & -0.05 & -0.04 & -0.04 & -0.06 \\
\hline Risk Premium & Mean & $4.28 \%$ & $4.02 \%$ & $4.19 \%$ & $6.74 \%$ \\
\hline Cons.Growth $(B)$ & Std. Dev. & $5.11 \%$ & $4.61 \%$ & $4.46 \%$ & $5.80 \%$ \\
\hline
\end{tabular}


Table 7: Asset pricing and aggregate consumption moments from the baseline model and the model with low aggregate uncertainty $(s=0)$.

\begin{tabular}{|c|c|c|c|}
\hline Variable & Moment & Baseline & $s=0$ \\
\hline Riskless Rate & Mean & $1.72 \%$ & $2.74 \%$ \\
& Std. Dev. & $3.07 \%$ & $0.11 \%$ \\
& AR(1) & 0.88 & 0.68 \\
\hline Equity Return & Mean & $6.05 \%$ & $4.06 \%$ \\
& Std. Dev. & $16.31 \%$ & $0.98 \%$ \\
& AR(1) & -0.05 & 0.33 \\
\hline Risk Premium & Mean & $4.33 \%$ & $1.32 \%$ \\
\hline Cons.Growth (S) & Std. Dev. & $4.91 \%$ & $1.75 \%$ \\
\hline Cons. Growth (NS) & Std. Dev. & $2.32 \%$ & $0.81 \%$ \\
\hline
\end{tabular}


Table 8: Asset pricing and consumption moments from the data and from the model with different levels of government debt (debt to GDP ratio, $B / Y$ ).

The asset pricing data is taken from Campbell (1999) while the consumption data is from Vissing-Jørgensen (2002a). The results from the model are reported in columns one through three. Column one (" $B / Y=40 \%$ ") is our baseline model. Column two (" $B / Y=15 \%$ (i)") reports the results for the same parameter values as the baseline calibration except that $B / Y$ is equal to $15 \%$. Column three (" $B / Y=15 \%$ (ii)") also assumes $B / Y$ equal to $15 \%$ but uses parameters values calibrated under this assumption. More precisely, the discount factor $\beta$ is now equal to 0.98 (without mortality adjustment).

\begin{tabular}{|c|c|c|c|c|c|}
\hline Variable & Moment & $\mathrm{B} / \mathrm{Y}=40 \%$ & $\mathrm{~B} / \mathrm{Y}=15 \%(\mathrm{i})$ & $\mathrm{B} / \mathrm{Y}=15 \%$ (ii) & Data \\
\hline Riskless Rate & Mean & $1.72 \%$ & $-0.04 \%$ & $1.35 \%$ & $1.58 \%$ \\
& Std. Dev. & $3.07 \%$ & $3.32 \%$ & $3.00 \%$ & $5.33 \%$ \\
& AR(1) & 0.88 & 0.87 & 0.87 & 0.52 \\
\hline Equity Return & Mean & $6.05 \%$ & $5.18 \%$ & $6.77 \%$ & $8.31 \%$ \\
& Std. Dev. & $16.31 \%$ & $16.29 \%$ & $16.33 \%$ & $19.81 \%$ \\
& AR(1) & -0.05 & -0.05 & -0.05 & -0.06 \\
\hline Risk Premium & Mean & $4.33 \%$ & $5.60 \%$ & $5.42 \%$ & $6.74 \%$ \\
\hline Cons.Growth (S) & Std. Dev. & $4.91 \%$ & $5.72 \%$ & $5.23 \%$ & $5.80 \%$ \\
\hline Cons. Growth (NS) & Std. Dev. & $2.32 \%$ & $2.35 \%$ & $2.97 \%$ & $3.96 \%$ \\
\hline
\end{tabular}


Table 9: Changes in the model implied moments from perturbations in the preference parameters.

The changes are measured relative to the values obtained in the baseline model $\left(\psi^{B}=0.4\right.$, $\beta=0.99$ and $\rho^{B}=5$ ). All other parameter values are those used in the baseline model.

\begin{tabular}{|c|c|c|c|}
\hline Moment & $\psi^{B}=0.3$ & $\beta=0.98$ & $\rho^{B}=4$ \\
\hline Mean Riskless Rate & $2.03 \%$ & $1.63 \%$ & $1.18 \%$ \\
Std. Dev. Riskless Rate & $0.11 \%$ & $-0.22 \%$ & $-0.24 \%$ \\
\hline Mean Equity Return & $1.97 \%$ & $1.57 \%$ & $0.81 \%$ \\
\hline Mean Risk Premium & $-0.06 \%$ & $-0.07 \%$ & $-0.37 \%$ \\
\hline Std. Dev. Cons. Growth (Stock.) & $-1.13 \%$ & $-0.32 \%$ & $-0.25 \%$ \\
\hline Std. Dev. Cons. Growth (Non-Stock.) & $-0.07 \%$ & $-0.29 \%$ & $-0.05 \%$ \\
\hline Capital-Output Ratio & $-9.86 \%$ & $-9.14 \%$ & $-4.67 \%$ \\
\hline Stock Market Participation Rate & $-0.17 \%$ & $-0.34 \%$ & $-0.12 \%$ \\
\hline
\end{tabular}


Table 10: Changes in the model implied moments from perturbations in the technology parameters.

The changes are measured relative to the values obtained in the baseline model $\left(\sigma_{u}=\right.$ $0.01, \pi=2 / 3$ and $\delta=0.1$. All other parameter values are those used in the baseline model.

\begin{tabular}{|c|c|c|c|}
\hline Moment & $\sigma_{u}=0.02$ & $\pi=0.8$ & $\delta=0.08$ \\
\hline Mean Riskless Rate & $-0.01 \%$ & $-0.01 \%$ & $0.22 \%$ \\
Std. Dev. Riskless Rate & $0.00 \%$ & $0.00 \%$ & $0.43 \%$ \\
\hline Mean Equity Return & $-0.01 \%$ & $-0.01 \%$ & $0.76 \%$ \\
\hline Mean Risk Premium & $0.00 \%$ & $0.00 \%$ & $0.54 \%$ \\
\hline Std. Dev. Cons. Growth (Stock.) & $-0.01 \%$ & $0.00 \%$ & $0.78 \%$ \\
\hline Std. Dev. Cons. Growth (Non-Stock.) & $0.02 \%$ & $-0.01 \%$ & $-0.02 \%$ \\
\hline Capital-Output Ratio & $0.08 \%$ & $0.04 \%$ & $7.87 \%$ \\
\hline Stock Market Participation Rate & $-0.02 \%$ & $0.02 \%$ & $0.23 \%$ \\
\hline
\end{tabular}




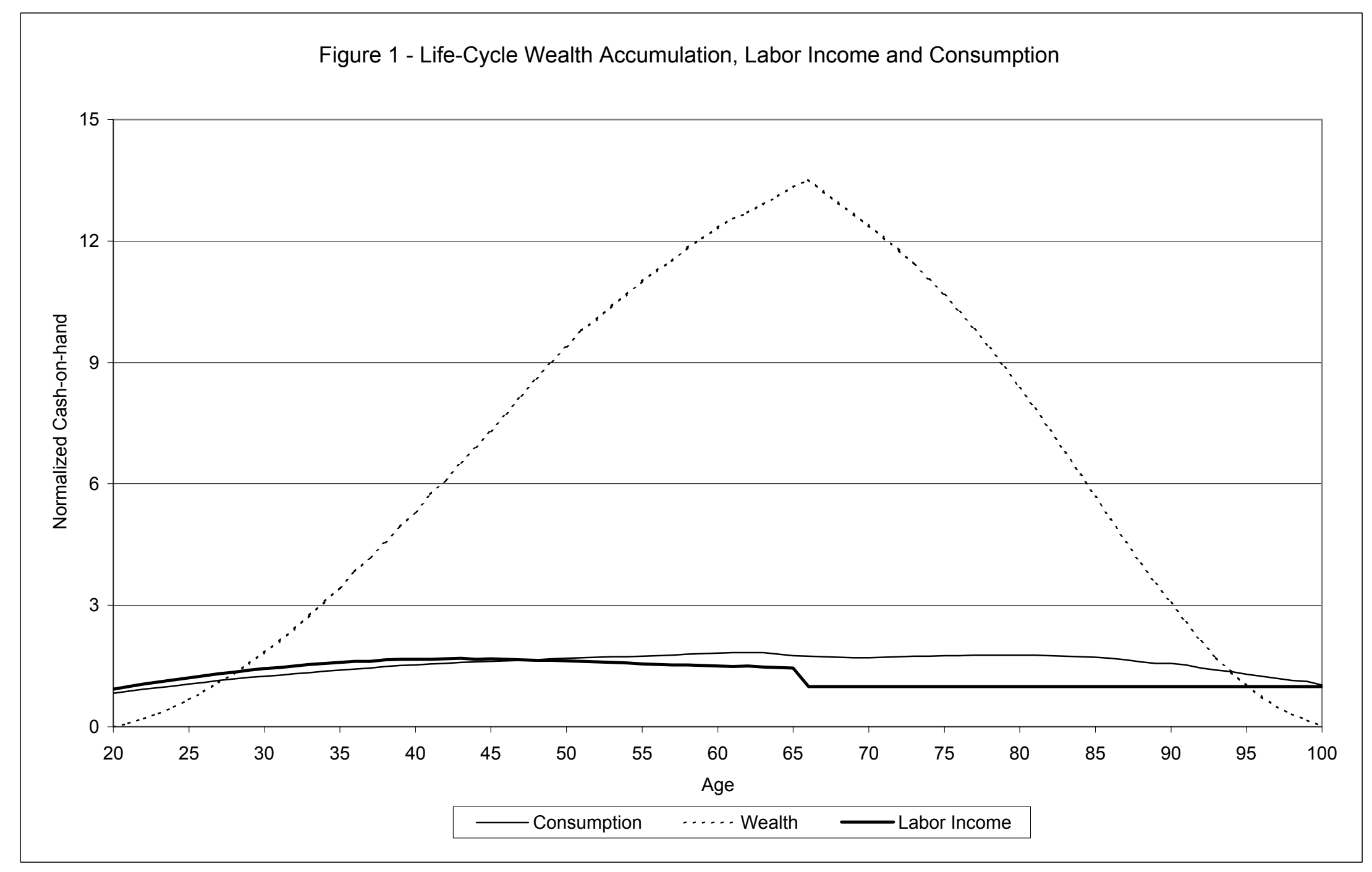

